\title{
Gobernanza: vigilancia y participación en la Reserva de la Biosfera Los Tuxtlas, Veracruz
}

\author{
Governance: Surveillance and Participation in \\ Los Tuxtlas Biosphere Reserve, Veracruz
}

\author{
Jorge Cueto-García* (iD) https://orcid.org/0000-0002-6090-3768 \\ Ludger Brenner ${ }^{* *}$ (i) https://orcid.org/0000-0003-1052-9007
}

\begin{abstract}
Resumen
Objetivo: con base en el concepto de gobernanza ambiental, analizar el Programa de Vigilancia Ambiental Participativa en la Reserva de la Biosfera Los Tuxtlas, que operó entre 1999 y 2015. Metodología: sobre la base de un análisis sistemático de entrevistas cualitativas con informantes clave, se indaga la legitimidad, la justicia ambiental y la efectividad de dicho programa. Resultados: a pesar de que los principios de gobernanza no se alcanzaron en su totalidad, el programa tiene potencial para promover de manera efectiva un régimen incluyente de gobernanza ambiental, lo cual lo hace valioso para el manejo de reservas de biosfera, desde la perspectiva de la Organización de las Naciones Unidas. Limitaciones: sin embargo, hacen falta estudios comparativos a escala nacional para analizar los resultados de las diversas intervenciones gubernamentales. Valor: el estudio constituye un referente para otras reservas donde opera el Programa de Vigilancia Ambiental Participativa. Conclusiones: sería útil una nueva fase de implementación del programa en la Reserva de Biosfera Los Tuxtlas y en otras reservas.

Palabras clave: reservas de biosfera; Reserva de la Biosfera Los Tuxtlas; gobernanza; participación; comités de vigilancia.
\end{abstract}

\begin{abstract}
Objective: to analyze, using the concept of environmental governance, the Participative Environmental-Surveillance Committees Program in Los Tuxtlas Biosphere Reserve, which operated from 1999 to 20I5. Methodology: a systematic qualitative analysis of interviews with key stakeholders, we studied the legitimacy, environmental justice and effectiveness of this program. Results: although these governance principles were not fully observed, the program has the potential to effectively contribute to promote an inclusive governance regime, which makes it valuable from the United Nations' view on the management of biosphere reserves. Limitations: further similar studies are needed in order to compare the outcomes of this governmental program at the national level. Value: our study serves as a reference for other reserves in which the program is implemented. Conclusions: we consider useful a new phase of implementation of this program in Los Tuxtlas Biosphere Reserve and in other protected areas.

Keywords: biosphere reserves; governance; participation; surveillance committees.
\end{abstract}

Cómo citar: Cueto-García, J., y Brenner, L. (202I). Gobernanza: vigilancia y participación en la Reserva de la Biosfera Los Tuxtlas, Veracruz. región y sociedad, 33, el 456. doi: 10.22198/rys2021/33/1456

*Autor para correspondencia. TH Köln-University of Applied Sciences, Institute for Technology and Resources Management in the Tropics and Subtropics. Betzdorfer Straße 2, 50679 Köln (Deutz) Germany. Correo electrónico: cuetogj@gmail.com

** Universidad Autónoma Metropolitana, Unidad Iztapalapa, Departamento de Sociología. San Rafael Atlixco Núm. 186, Colonia Vicentina, Delegación Iztapalapa, C. P. 09340, Ciudad de México, México. Correo electrónico: bren@xanum.uam.mx

Recibido: 6 de marzo de 2021

Reevaluado: 5 de agosto de 2021

Aceptado: 16 de noviembre de 2021

Liberado: 27 de diciembre de 2021

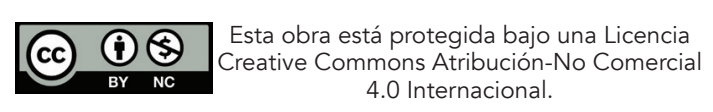

https://regionysociedad.colson.edu.mx:8086/index.php/rys/index 


\section{Introducción}

Las reservas de biosfera (RB) son áreas naturales protegidas que buscan conciliar la conservación de los recursos naturales con el desarrollo socioeconómico regional (Batisse, 1993; Organización de las Naciones Unidas para la Educación, la Ciencia y la Cultura [UNESCO], 2016) y promover un régimen de gobernanza con la participación de los habitantes locales.

El concepto de gobernanza es descriptivo-analítico. Se refiere a procesos complejos, formales e informales, entre diversos actores sociales e instituciones, que derivan en la toma de decisiones y en acciones también formales e informales (Brenner, 2015; Stocker, 1998). Es un concepto rico que integra aspectos diferentes, propios de las relaciones sociales, políticas y de poder (Aydin, 2020; Stocker, 1998). De acuerdo con el ámbito de aplicación y con sus objetivos empíricos y analíticos, se distinguen diferentes tipos de gobernanza, entre ellos la gobernanza ambiental (Alfie, 2011).

En el ámbito de las RB, el término está muy ligado a la inclusión y consideración de los habitantes de esas zonas en la toma de decisiones, ya que con frecuencia el acceso a los recursos naturales y sus usos tradicionales están restringidos o prohibidos por motivos de conservación (Brenner, 2009; UNESCO, 2016).

El presente artículo tiene en cuenta aquellos aspectos propios del estudio de caso y no la totalidad de los aspectos referentes al concepto. Se enfatiza en el carácter normativo de la gobernanza aplicada a los casos relativos al medio ambiente y a los recursos naturales. Así, el trabajo se centra en tres elementos relacionados con el concepto: legitimidad, justicia ambiental y efectividad. El análisis se enfoca en un componente de la gobernanza de la Reserva de la Biosfera Los Tuxtlas (RBLT), el Programa de Vigilancia Ambiental Participativa (PVAP), y no en la totalidad de los mecanismos que conforman la gobernanza del área natural protegida.

Para Adger, Brown, Fairbrass, Jordan, Paavola, Rosendo y Seyfang (2003), un régimen adecuado de gobernanza ambiental supone legitimidad, justicia ambiental y efectividad. El Plan de Acción de Lima (2016) para el manejo de reservas de biosfera refrenda esta visión de gestión a escala internacional y promueve la implementación de estos principios en todas las RB pertenecientes a la Red Internacional de Reservas de Biosfera (UNESCO, 2016).

En el contexto mexicano, la legislación y las instituciones también reconocen dichos principios (Comisión Nacional de Áreas Naturales Protegidas [CONANP], 2018; Secretaría de Medio Ambiente y Recursos Naturales [SEMARNAT], 2012), y desde los primeros años de implementación de las RB en territorio nacional se ha puesto el énfasis en la inclusión y la participación local y regional en su manejo (CONANP, 2018; Halffter, 1998 y 2011). Ejemplo de ello son las primeras RB mexicanas denominadas Mapimí y La Michilía en los estados de Chihuahua y Durango, respectivamente (Halffter, 1988).

En el Programa de Conservación y Manejo (PCM) de la RBLT, decretada en 1998, se establece que la participación de los actores sociales es un elemento prioritario para las políticas de conservación (CONANP, 2006). No obstante, ésta se concibe en general de distintas maneras, y varía la influencia de la sociedad 
civil en materia de gestión y toma de decisiones, a menudo en función de los intereses de quienes la promueven (Cano, 2008).

En cumplimiento de la Ley General del Equilibrio Ecológico y la Protección al Ambiente (LGEEPA) (SEMARNAT, 2012), el PCM contempla mecanismos para la participación local que deben implementar la CONANP y la Procuraduría Federal de Protección al Ambiente (PROFEPA). Esto refleja la visión de manejo de RB de la UNESCO, que aboga por una participación activa y efectiva de las poblaciones locales (UNESCO, 2016).

En el PCM (CONANP, 2006), el componente de participación se aborda en complemento con el de vigilancia. La estrategia concreta para ello es la implementación del Programa de Vigilancia Ambiental Participativa (PVAP).

El PVAP opera con comités de vigilancia integrados por los miembros de las comunidades locales. Están conformados por diez integrantes voluntarios, como mínimo. Los interesados pasan por una fase de capacitación y otra de evaluación. Después la PROFEPA los acredita como integrantes del comité de vigilancia de su comunidad. Los comités deben presentar un programa de trabajo, que la PROFEPA debe aprobar, en el cual se detallen sus actividades. Dicha institución es responsable de brindar apoyo, supervisar y evaluar las actividades de los comités (Subprocuraduría de Recursos Naturales, s. f.).

Los comités son un instrumento clave para la protección ambiental (CONANP, 2006). Tienen el objetivo de "lograr la participación decidida, informada y responsable de la sociedad [...] en la vigilancia e inducción del cumplimiento de la ley ambiental" (Subprocuraduría de Recursos Naturales, s. f., p. 5). Además, el Manual de vigilancia ambiental participativa indica que la PROFEPA tiene la función de incentivar la participación social en la "planeación, ejecución, evaluación y vigilancia de la política ambiental y de los recursos naturales" (Subprocuraduría de Recursos Naturales, s. f., p. 6).

Con base en esto, se observa en el PVAP y en sus comités un elemento clave de la gobernanza ambiental de la RBLT relacionado con las formas de participación y con las formas de acceso a los recursos naturales, ya que su función es, mediante un proceso participativo, vigilar que los recursos de la reserva se aprovechen de acuerdo con el PCM.

En la RBLT se puso en marcha el PVAP en 1999, que fue importante en la gestión de la reserva y en la gobernanza ambiental a escala regional. A pesar de que sus logros no fueron contundentes, contribuyó incluyendo a la población local en esfuerzos de conservación y asegurando en cierta medida el cumplimiento de las normas de aprovechamiento y protección de la RBLT (PCM) (Cueto-García, 2016).

A más de cinco años de la suspensión del PVAP a escala local por causas extrainstitucionales ${ }^{1}$ y del consecuente incremento del tráfico de especies silvestres y de la cacería -acciones que detectaron los actores sociales que tienen presencia en la región (Reyes, 2016; comunicación personal con pobladores

Se presume que en 2015 el delegado de la PROFEPA fue víctima de una desaparición forzada. Desde entonces, el PVAP fue suspendido de facto y con ello se incrementó la incidencia de delitos ambientales (Reyes, 2016). 
locales, investigadores y organizaciones ambientales en Los Tuxtlas ${ }^{2}$ ) -, resulta relevante indagar las formas concretas en las que el PVAP contribuía y, sobre todo, en las que podría contribuir en la actualidad al establecimiento de un régimen apropiado de gobernanza ambiental en la RBLT.

Este estudio muestra una perspectiva de los alcances del PVAP como instrumento de gobernanza ambiental en la RBLT y a escala nacional, porque el programa se implementa en diversos territorios y reservas de biosfera (SEMARNAT, 2020). No obstante, cada caso debe analizarse y entenderse en su propio contexto.

Este análisis permite apreciar aspectos relacionados con la legitimidad de la normativa ambiental indagando en la forma en que las autoridades ambientales conciben e implementan la participación social, elemento fundamental para la legitimidad en el marco de la gobernanza (Adger et al., 2003; Stoll-Kleemann y O’Riordan, 2002). Paralelamente, permite observar el acatamiento de las disposiciones de protección ambiental y la operatividad del programa a escala local, así como el panorama de la justicia ambiental relacionado con la distribución del acceso a los recursos naturales y con los efectos negativos derivados de las decisiones en materia ambiental (Adger et al., 2003; Hervé, 2010; Riechmann, 2003). Por último, es posible examinar la efectividad de esta estrategia institucional para la buena gobernanza ambiental y su valor como instrumento de gestión.

El objetivo es conocer de qué manera el PVAP contribuye a la gobernanza ambiental en las reservas de biosfera. Partiendo de la teoría sobre gobernanza y tomando como ejemplo el caso de la RBLT, se plantean aquí las siguientes preguntas. ¿Cómo contribuía el PVAP a la instauración de un régimen de gobernanza ambiental legítimo, justo y efectivo en la RBLT? ¿Qué aspectos impidieron que el PVAP tuviera mayor efectividad? ¿Es pertinente en el contexto actual retomar el PVAP para dar soporte a la legitimidad, justicia y efectividad a la gobernanza ambiental de la RBLT?

A continuación, se presenta el enfoque teórico y los conceptos clave de la gobernanza ambiental pertinentes para nuestro estudio. Luego se describe la RBLT, se explica la metodología, se exponen y se discuten los resultados y, al final, se responden las preguntas de investigación.

\section{Reservas de biosfera y gobernanza ambiental}

Las RB se concibieron como instrumentos de gestión para impulsar prácticas de desarrollo sustentable que buscan trascender antiguas formas de gestión restrictivas y excluyentes en términos sociales (Adams y Hutton, 2007; Batisse, 1993; Vega-Leinert y Stoll-Kleemann, 2012). Desde esta perspectiva, resulta trascendental la mitigación de conflictos de interés mediante la participación y el diálogo entre los usuarios de los recursos naturales, las comunidades locales,

2 Con base en entrevistas de seguimiento al caso de estudio, se obtuvo información del incremento de problemáticas ambientales en la zona. Dichas entrevistas se llevaron a cabo el 6 de octubre de 2020 y el 4 de octubre de 2021. 
los científicos, los tomadores de decisiones, las instituciones públicas y otros actores (UNESCO, 2016).

El concepto de gobernanza se refiere a una modalidad de gestión en la que los actores sociales tienen un grado adecuado de injerencia en los procesos de toma de decisiones y en la ejecución de acciones consecuentes (Alfie, Díaz y Castañeda, 2011; Fontaine y Velasco, 2011). Lo han promovido instituciones financieras internacionales, como el Banco Mundial (BM), el Banco Interamericano de Desarrollo (BID), la Organización para la Cooperación y el Desarrollo Económicos (OCDE) y el Banco Europeo para la Reconstrucción y Desarrollo (BERD), las cuales han tenido un rol determinante en la definición del término para impulsar gestiones públicas más democráticas, transparentes y eficaces (BM, 1992; Lancaster, 1993). En materia ambiental, la UNESCO, a través del modelo de RB, también ha promovido esta gobernanza desde 1970 (Batisse, 1993; UNESCO, 2016).

Cada institución enfatiza aspectos distintos. Para el BM, es importante promover procesos adecuados de diseño y aplicación de políticas públicas (BM, 1992). El BID pone el énfasis en el rol de la sociedad civil y del sector privado en las decisiones públicas (Milano, 2017). La OCDE destaca la efectividad y la prevalencia del derecho en las acciones gubernamentales (García, 2010). Para el BERD, son importantes la democracia y el respeto a los derechos humanos (Brock, 2020). La UNESCO subraya la inclusión de las poblaciones locales en los procesos de toma de decisiones ambientales (UNESCO, 2016).

El debate internacional sobre gobernanza ambiental refrenda la importancia de estos principios (Abrams, Borrini, Gardner y Heylings, 2003; Adger et al., 2003). En México, esto se observa en la legislación y en la política ambiental, que hacen hincapié en la democracia, en la participación de la sociedad civil y en la justicia de las acciones institucionales de conformidad con la Ley General del Equilibrio Ecológico y la Protección al Ambiente (LGEEPA) (SEMARNAT, 2012). La PROFEPA y la CONANP manifiestan la importancia de estos principios de gobernanza (CONANP, 2020; Halffter, 1981; Subprocuraduría de Recursos Naturales, s. f.).

Puesto que el PVAP tenía la intención de impulsar la participación social en el marco de la protección de la biodiversidad y salvaguardar el derecho ambiental, ${ }^{3}$ analizar su implementación permite observar tres aspectos clave de la gobernanza ambiental: la legitimidad, que se alcanza con el nivel de participación social y con el acatamiento de las decisiones tomadas en conjunto; la justicia ambiental, puesto que en el escrutinio de su implementación se puede observar si existían situaciones que vulneraban el derecho ambiental de los habitantes de la RBLT; y la efectividad, ya que podrá determinarse hasta qué punto y de qué forma el PVAP alcanzó sus objetivos y cómo contribuyó a los procesos de buena gobernanza de la RBLT.

3 El PVAP refleja la misión institucional de la PROFEPA: "Procurar la justicia ambiental a través del estricto cumplimiento de la Ley, desterrando a la vez impunidad, corrupción e indolencia y vacíos de autoridad, haciendo partícipes de esta lucha a todos los sectores de la sociedad y a los tres niveles de gobierno, bajo los más puros principios de equidad y justicia" (Subprocuraduría de Recursos Naturales, s. f., p. 5). 


\section{Legitimidad}

La legitimidad es un principio que requiere un tipo de participación que permita definir en conjunto, sociedad civil e instituciones gubernamentales, las normas que regirán el orden público, puesto que incentiva su acatamiento. Es decir, las normas deben representar el interés del sector civil para que se respeten y con ello alcanzar su legitimidad (Ferrando, 1971; Rodríguez-Franco, Rodríguez, Muñoz, García y Vázquez, 2020). Por eso la participación es fundamental en los procesos de toma de decisiones públicas (Stoll-Kleemann y O’Riordan, 2002).

Sin embargo, la participación puede promoverse de diversas formas y alcanzar o no la legitimidad. Con base en Arnstein (1969), Cano (2008) y Pretty (1995), se ha elaborado la tabla 1, donde se muestra una síntesis de las diversas formas de participación y su injerencia en la toma de decisiones. Aquí se utilizan estos elementos para proponer la siguiente tipología: A, B-, B+, C- y C+. Y, haciendo una distinción tipográfica, se señalan las formas que son relevantes para nuestro caso de estudio.

Se observa un tipo de participación que va desde una forma pasiva hasta la cooperación. En este tipo de participación, el involucramiento de la sociedad civil implica cuando menos la obtención de información sobre las medidas que se pretenden aplicar. Por lo general, la opinión de ésta se escucha pero sin que necesariamente influya en las decisiones. Al conjunto de estas formas, se las identifica aquí como de tipo $B$, y hacemos una subdistinción (véase tabla 1).

Los casos en los que la participación no conlleva un rol activo por parte de sectores de la sociedad civil y se incluye a éstos sólo como receptores de información o en consultas que no derivan en la incorporación de su opinión en la toma de decisiones, se los identifica como de tipo B-. Los casos en los que la participación conlleva un rol activo por parte de los sectores sociales y en los que además puede conseguirse un beneficio económico o en especie a cambio de su colaboración, se los identifica como de tipo B+. Cabe subrayar que, en este último tipo, la participación tampoco influye de manera directa en los procesos de toma de decisiones; por lo tanto, no tiene un impacto positivo en términos de legitimidad.

La figura 1 muestra, con base en lo explicado sobre participación y acatamiento (Ferrando, 1971; Stoll-Kleemann y O'Riordan, 2002) y en los tipos de participación de la tabla 1, el proceso que se requiere para alcanzar la condición de legitimidad, que aquí se considera como una variable categórica.

Para alcanzar la legitimidad, es necesario que las decisiones tomadas, expresadas en políticas públicas o regulaciones gubernamentales, sean acatadas plenamente. Esto requiere que las personas sujetas a dichas normas vean sus intereses reflejados en ellas, lo cual se logra con los tipos de participación C- y $\mathrm{C}_{+}$, que tienen injerencia alta en los procesos de toma de decisiones.

Las formas de participación de tipo $\mathrm{B}+$, por tener injerencia potencial o media en la toma de decisiones, pueden o no reflejar el interés de una comunidad y por lo tanto alcanzar o no cierto nivel de acatamiento. Por eso no logran ser legítimas. 


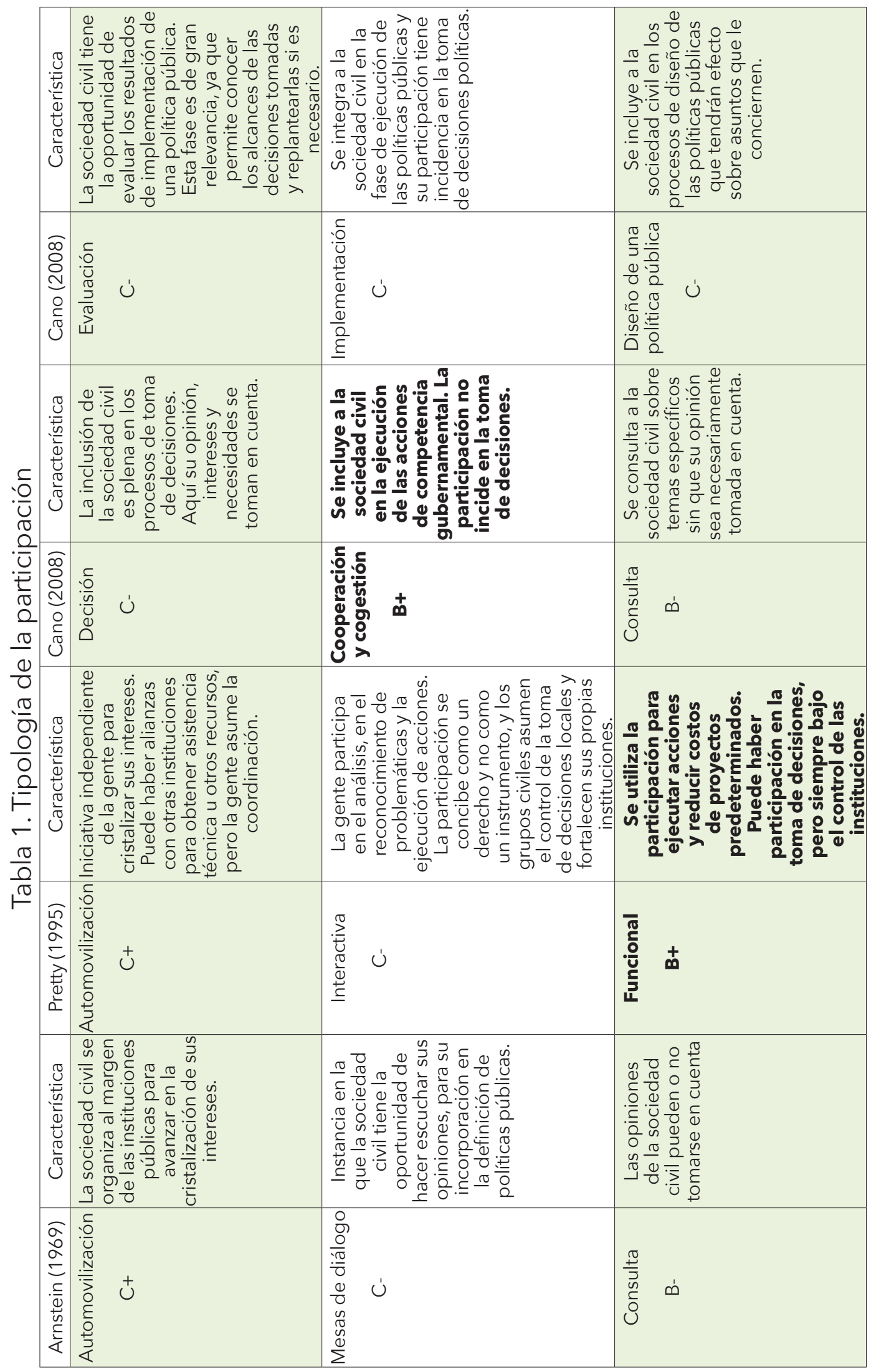




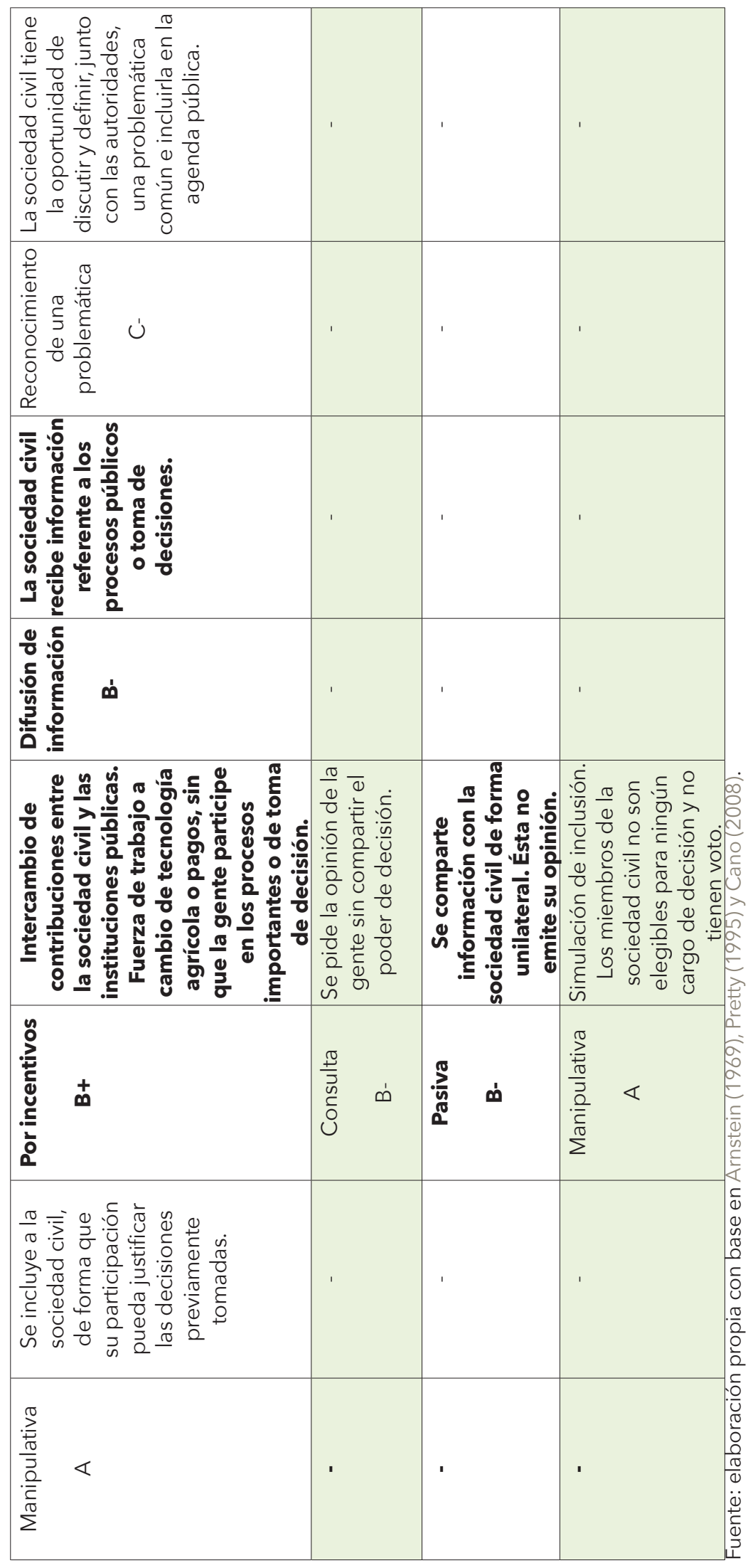


Figura 1. Diagrama de la participación, el acatamiento y la legitimidad

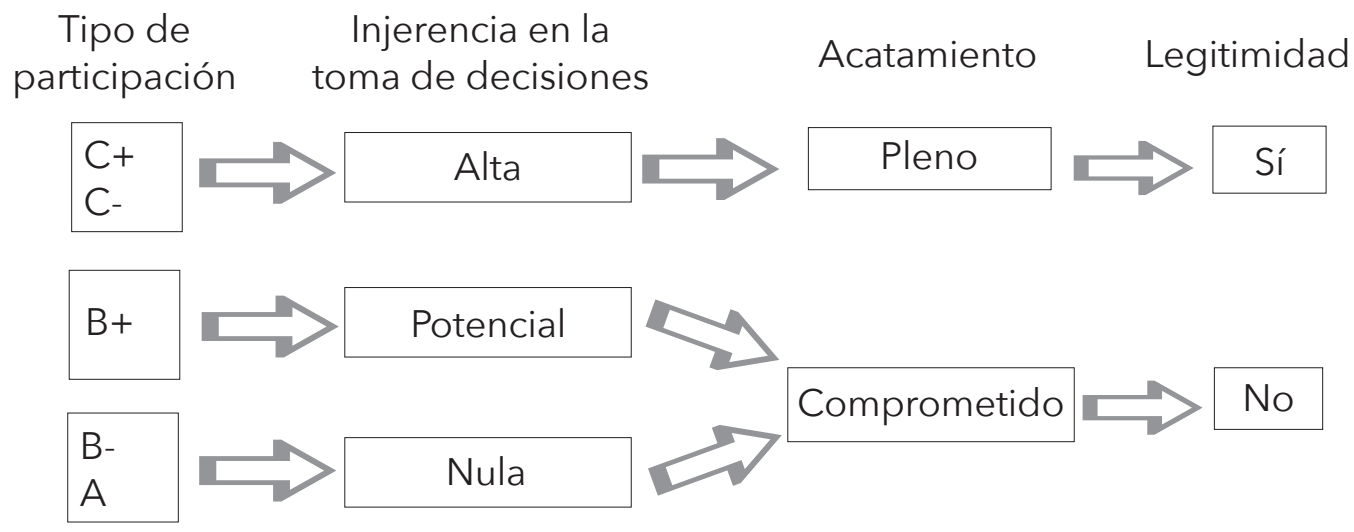

Fuente: elaboración propia con base en Arnstein (1969), Pretty (1995), Cano (2008), Ferrando (1971) y Stoll-Kleemann y O'Riordan (2002).

Las formas de participación incluidas en los tipos B- y A, al tener poca o ninguna injerencia en los procesos de toma de decisiones, no promueven el acatamiento de éstas y por lo tanto tampoco su legitimidad.

\section{Justicia ambiental}

El principio de justicia ambiental abarca los aspectos relativos a los conflictos de distribución de bienes naturales y a los efectos negativos de las decisiones ambientales entre los seres humanos de las generaciones presentes y las futuras, y entre éstos y otros seres vivos (Martínez-Alier, 1996; Riechmann, 2003). La tabla 2 muestra, delimitando la discusión al caso de estudio, los aspectos significativos de este principio.

Hay nueve principios de justicia ambiental que aquí se han organizado de manera general en cuatro grupos. Al primer grupo lo denominamos acceso e incluye los principios 1.2, 3.1 y 3.2 (véase tabla 2). Su característica es que el conjunto de principios procura garantizar que todos los sectores sociales tengan acceso al mínimo de recursos naturales necesarios para satisfacer sus necesidades humanas básicas; también que no haya diferencias en el acceso a dichos recursos entre los distintos sectores poblacionales debido a sus condiciones étnicas o socioeconómicas.

El segundo grupo es distribución de impactos e incluye los principios 1.1 y 2.1. La característica de éstos es que pretenden garantizar que las decisiones públicas relacionadas con el ambiente no generen consecuencias que sean asumidas exclusiva o mayoritariamente por ciertos sectores poblacionales por razones étnicas o socioeconómicas. 


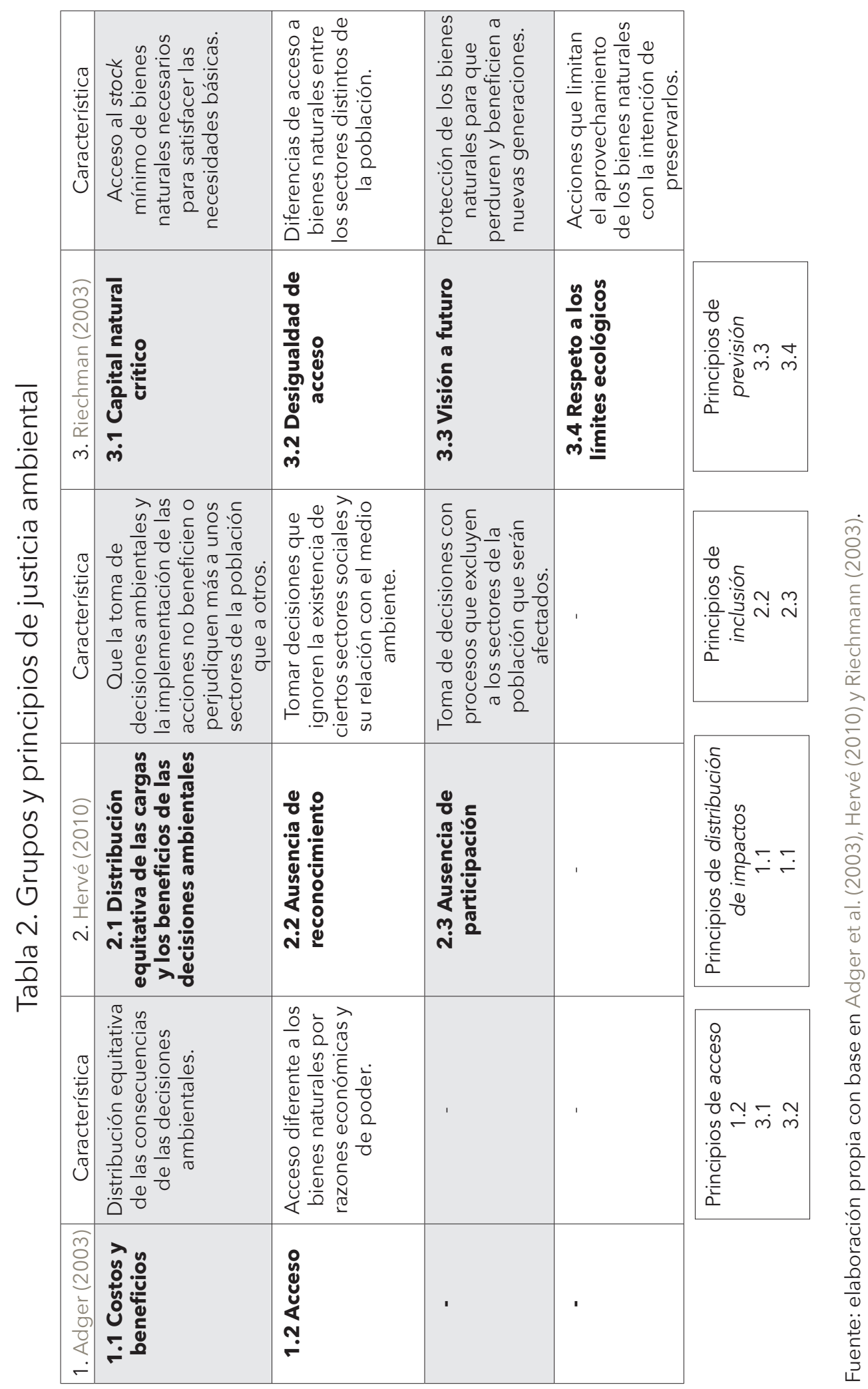


El tercer grupo es inclusión y lo conforman los principios 2.2 y 2.3. Su característica es que buscan dar garantía de que las decisiones en materia ambiental se tomen considerando las necesidades, los intereses y las opiniones de las poblaciones sobre las que recaen.

Al cuarto grupo lo llamamos previsión y lo conforman los principios 3.3 y 3.4. Su característica es que trata de asegurar la preservación de los bienes naturales para el beneficio de futuras generaciones.

Con base en lo anterior, puede afirmarse que para que en un régimen de gobernanza exista la justicia ambiental, los aspectos incluidos en cada uno de estos grupos deben estar garantizados (véase figura 2).

Figura 2. Diagrama de justicia ambiental

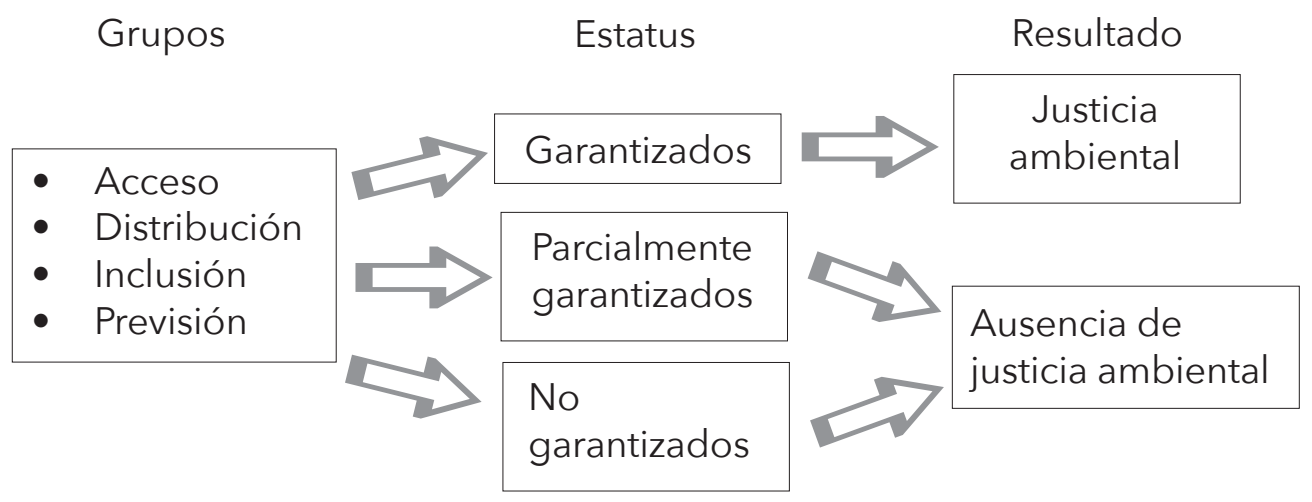

Fuente: elaboración propia con base en Adger et al. (2003), Riechmann (2003) y Hervé (2010).

Por razones analíticas, la justicia ambiental se entiende en el presente texto como una variable categórica que se alcanza cuando mediante conductos gubernamentales los sectores sociales en cuestión gozan de manera sistemática del cumplimiento de los principios de los cuatro grupos descritos. En tal caso se dice que dichos principios están garantizados. Pero, por otro lado, el análisis no considera los principios por nivel de importancia o de prioridad.

Si sólo una parte de estos principios se cumplen, por omisiones sistemáticas o eventuales, se considera que se garantizan pero sólo de manera parcial, en cuyo caso se da la ausencia de justicia ambiental. Lo mismo sucede si las acciones gubernamentales omiten de forma sistemática los principios de los cuatro grupos. Es importante aclarar que lo anterior responde a una decisión metodológica correspondiente al caso de estudio. La importancia y el peso de cada principio están en función de cada caso particular.

\section{Efectividad}

El principio de efectividad se refiere al grado en que una política pública cumple con los lineamientos plasmados en su diseño - teniendo en cuenta aspectos 
formales y operativos- y al nivel en el que alcanza los objetivos para los cuales fue creada (Adger et al., 2003).

Se sabe que las políticas públicas que tienen mayor nivel de efectividad son aquellas que incluyen otros actores sociales, además de los gubernamentales. Estos últimos tienen un rol fundamental por ser quienes coordinan el diseño y la implementación de esas políticas. Sin embargo, el papel de otros actores sociales es determinante durante todo el ciclo de éstas: el reconocimiento de un problema, el diseño de la política para resolverlo y su puesta en marcha (Cano, 2008; Jacob, King, Mangalagiu y Rodríguez-Labajos, 2019).

El presente estudio toma, como elementos base de la efectividad, los objetivos de participación y vigilancia del PVAP. La figura 3 muestra de manera esquemática el enfoque.

Figura 3. Diagrama de efectividad

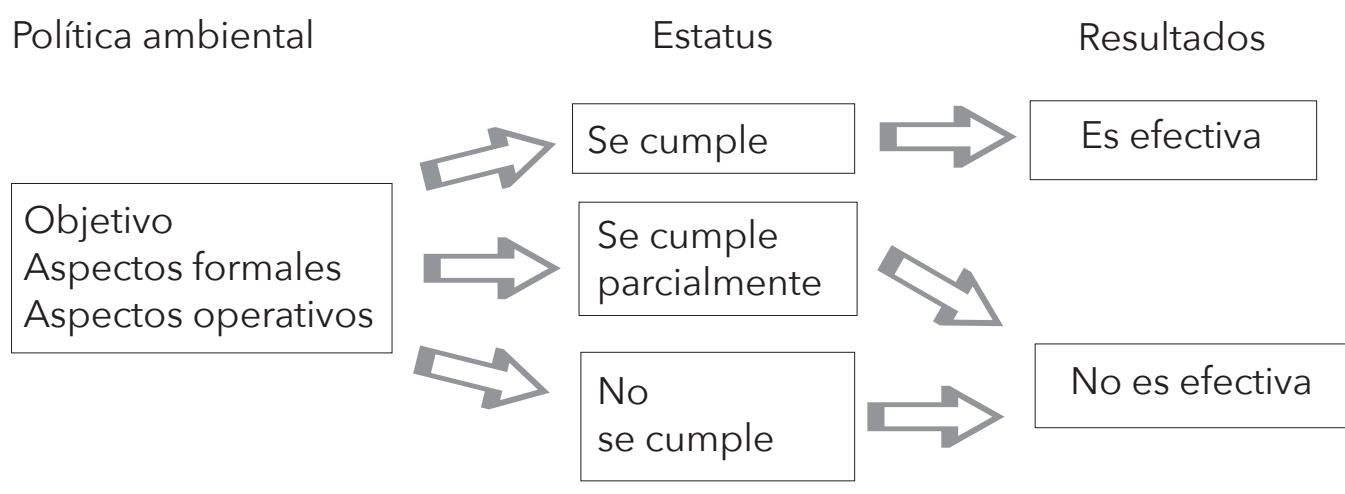

Fuente: elaboración propia con base en Adger et al. (2003).

\section{Área de estudio}

La RBLT fue decretada en 1998 y se localiza al sur del estado de Veracruz, México. Por su diversidad ecológica y social, se la considera prioritaria para la investigación y la conservación ambiental (CONANP, 2006). Su elección como área de estudio consideró la problemática social, en la que se destaca que la inclusión de los habitantes locales en procesos de toma de decisiones no se ha logrado de forma adecuada (Durand y Ruiz, 2009; Paré y Fuentes, 2007; Velázquez y Ramírez, 2015). En contraste, la existencia de estructuras institucionales de participación, como el Consejo Asesor y el PVAP, son relevantes para promover la inclusión de los actores locales (CONANP, 2006 y 2017).

El PCM establece como premisa la participación de los habitantes de la reserva y de otras personas interesadas en el aprovechamiento y la protección de los recursos. El PVAP busca utilizarse como instrumento para fortalecer la participación local en la gestión ambiental. Se contempla la realización de re- 
uniones con los habitantes de la RBLT, sin importar su condición de tenencia de la tierra, para conformar comités de vigilancia y así incluirlos en el manejo del área natural protegida (ANP). Las instancias gubernamentales deberían proporcionar recursos económicos y equipamiento de trabajo como botas y uniformes a los participantes del programa (CONANP, 2006).

La RBLT abarca partes de los municipios San Andrés Tuxtla, Catemaco, Soteapan, Tatahuicapan de Juárez, Pajapan, Santiago Tuxtla, Mecayapan y Ángel R. Cabada (CONANP, 2006). La tenencia de la tierra complejiza la dinámica de aprovechamiento y protección de los recursos naturales: hay colonias, tierras ejidales, propiedad privada y federal. Las medidas de protección y conservación ambiental, incluidas las expropiaciones realizadas tras el decreto del ANP, han afectado a sus habitantes (colonos, ejidatarios, avecindados y propietarios privados) (Diario Oficial de la Federación, 2009).

Figura 4. Mapa de comités de vigilancia en la Reserva de Biosfera Los Tuxtlas, 2012

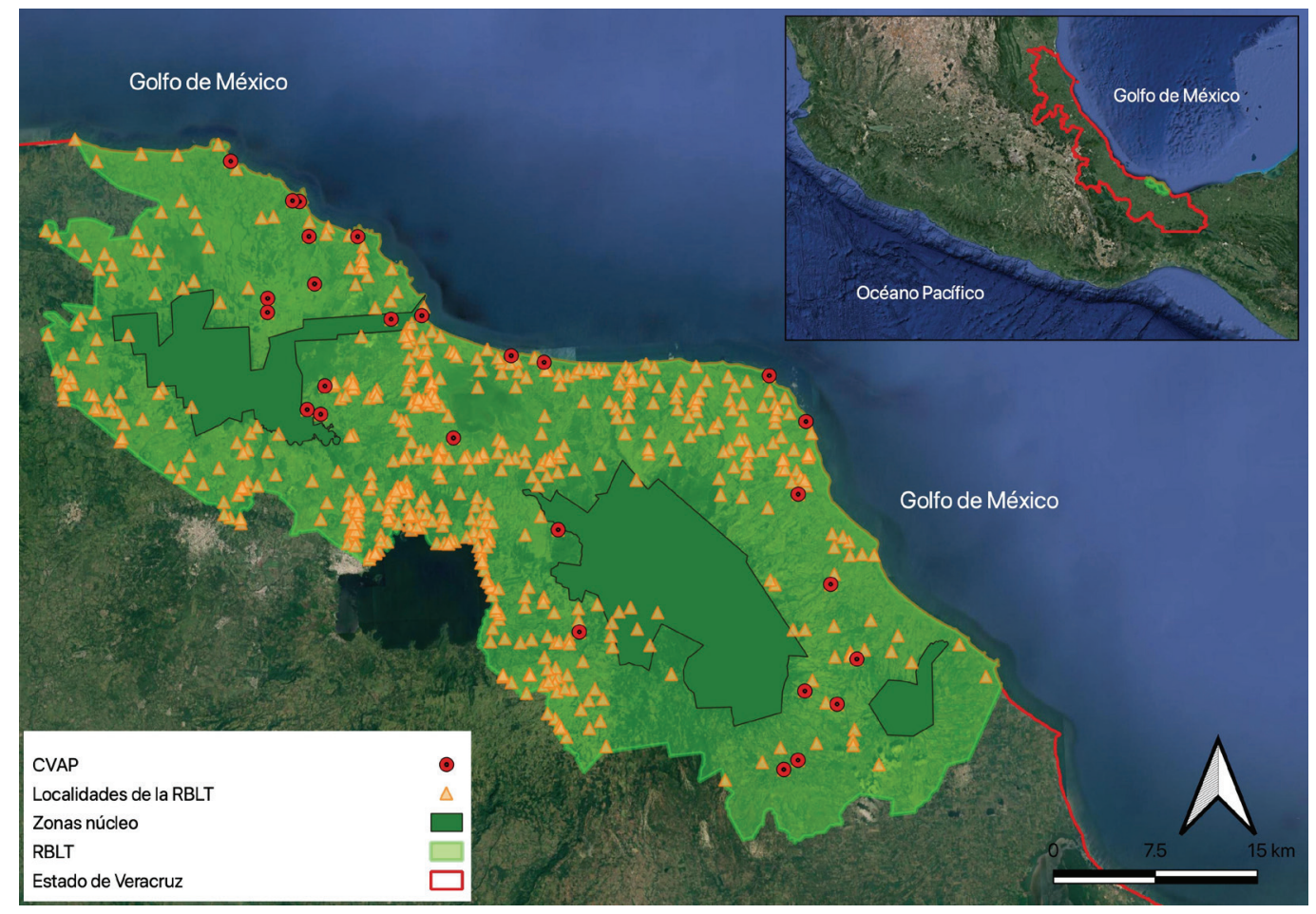

Fuente: elaboración de Jorge Cueto García, 2021, con base en los datos de la CONANP (2019 y 2021).

La situación económica para la mayoría de sus habitantes es desfavorable, porque las fuentes de empleo son escasas y los ingresos son insuficientes (CONANP, 2006; Cueto-García, 2016). Las principales actividades productivas son la ganadería, el turismo, la agricultura y la pesca (CONANP, 2006; Díaz, 2010; Paré y Fuentes, 2007). 
Algunos impactos ambientales importantes han ocurrido debido, sobre todo, a la ganadería (Guevara, Laborde y Sánchez, 1999; Hidalgo, 2009; Siemens, 2009), pero también al tráfico de especies de flora y fauna, a la tala para la agricultura y a la venta de madera. Algunas modalidades de pesca son también fuente de impactos ambientales (CONANP, 2006).

En el momento de la realización del trabajo de campo, había 27 comités de vigilancia ambiental participativa en 25 localidades y uno en la estación de investigación biológica bajo la responsabilidad de la Universidad Nacional Autónoma de México (UNAM), distribuidos en cinco municipios. Fueron conformados entre los años 1999 y 2011, y durante ese periodo promovieron la participación de un sector poblacional de la reserva en la vigilancia. Recibieron cursos de capacitación y denunciaron ante la PROFEPA casos de aprovechamientos de recursos naturales no permitidos por el PCM.

La suspensión de actividades de dicha institución a escala regional, debido a la presumible desaparición forzada del delegado en 2015 (Reyes, 2016), ocasionó el cese del PVAP. Algunos miembros de los comités continuaron sus actividades de vigilancia por interés propio (comunicación personal con habitantes de la RBLT). Sin embargo, aumentó la incidencia de aprovechamientos de recursos naturales no sustentables (Reyes, 2016; comunicación personal con investigadores expertos en la RBLT).

\section{Metodología}

Durante enero y abril de 2012, se realizaron y grabaron, con autorización de los entrevistados, 33 entrevistas semiestructuradas a las autoridades ambientales locales, integrantes de los comités de vigilancia ambiental participativa (CVAP) y a los actores sociales relevantes para el estudio.

Se emplearon tres guiones distintos, adaptados al perfil y a la posición de cada grupo de actores sociales. Además de los temas principales -legitimidad, justicia ambiental y efectividad del PVAP-, las preguntas abordaron aspectos contextuales, como el tiempo de residencia de los entrevistados en las comunidades, los cambios en la forma de vida tras el decreto de la RBLT y la importancia de la conservación ambiental. Se dio libertad a los entrevistados de relatar su experiencia (Robles, 2011) como habitantes de la reserva o como integrantes de un comité de vigilancia, de una ONG o de una institución pública, pero se hicieron preguntas directas cuando fue necesario.

Las entrevistas se transcribieron y el cuerpo del texto se asoció con códigos correspondientes a cada categoría analítica - legitimidad, justicia ambiental y efectividad-, preparados de forma inductiva (Vasilachis, 2006) con base en la teoría de gobernanza ambiental y en el contenido de las entrevistas. Con el software ATLAS.ti se realizó el análisis cualitativo de datos y los códigos se vincularon con fragmentos de las entrevistas que sirvieron como evidencia de las afirmaciones que se presentan en el artículo.

Durante septiembre y octubre de 2020 y enero de 2021, se realizaron entrevistas a distancia con dos antiguos integrantes de los comités de vigilancia, un 
experto adscrito a la UNAM y con la líder de una organización civil local, para tener una perspectiva actual y obtener información de la situación posterior a la suspensión del PVAP. Estas entrevistas fueron abiertas y se registraron en formato de audio. Estas entrevistas se transcribieron y analizaron de la misma forma que las entrevistas de la primera ronda. Todos los entrevistados de la segunda ronda tenían conocimiento del estudio y de la existencia de una primera fase de las entrevistas.

Se asignó una identificación (ID) a cada entrevista, compuesta por un número con base en el orden de realización, la fuente -institución (INST), asociación civil (AC), comité (COM), investigador (INV) y antiguo comité (ANT_COM) - y el año en que se llevó a cabo. Se usa la ID para referirse a las entrevistas dentro del presente texto. Se omite el nombre de las localidades de los comités de vigilancia para evitar señalamientos directos.

\section{Resultados}

Legitimidad: participación y acatamiento de la normativa ambiental a través del PVAP

Para mostrar las formas de participación que se observaron en la implementación del PVAP, se emplea el siguiente diagrama que incluye, con base en la información extraída de las entrevistas de campo (2012), las fases de conformación y puesta en marcha de los comités de vigilancia.

Figura 5. Tipos de participación en el PVAP

Fases de participación

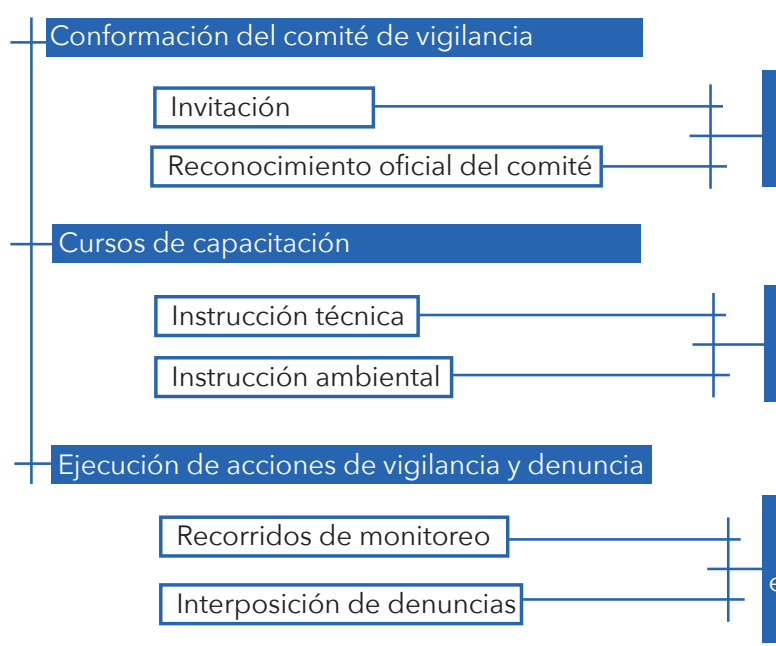

Formas de participación

Recepción de

información e

identificaciones

Recepción de

información

Funcional y

cooperación, con

ventual recepción

de incentivos
Tipo de participación

Fuente: elaboración propia, 2021. 
De acuerdo con las entrevistas, el proceso de conformación de los comités de vigilancia propició formas de participación que, conforme a la tipología propuesta (véase tabla 1), corresponden al tipo B-: participación pasiva y difusión de información. En este sentido, para dar a conocer y poner en marcha el PVAP, la PROFEPA organizó reuniones informativas en las comunidades e invitó a los habitantes locales a formar parte del programa.

Los interesados mayores de 18 años decidieron (o no) integrarse de forma voluntaria al programa. La organización de la estructura del comité en todos los casos fue independiente a la PROFEPA. Luego la institución otorgó identificaciones a los integrantes de los comités de vigilancia para formalizar su participación dentro del programa.

La fase de capacitación se identifica también con un tipo de participación B-, difusión de información. Ésta implicó la impartición de cursos por parte de la PROFEPA a los integrantes de los comités de vigilancia. Dichos cursos se diseñaron con el criterio de la institución, se impartieron en las localidades y se relacionaron casi siempre con aspectos técnicos para interponer denuncias de usos no sustentables de los recursos naturales y, en menor medida, con aspectos ambientales del entorno local.

Las capacitaciones ambientales tuvieron un impacto positivo en cuanto al cumplimiento de la normativa oficial, ya que con ellas incrementó la comprensión de algunos de los integrantes de los CVAP sobre los ecosistemas y las especies, y aumentó su interés en respetar las medidas de protección ambiental oficiales y en procurar que se hagan cumplir. Ésta es una observación importante, pues muestra que la difusión de información de este tipo puede contribuir al proceso de legitimación de la normativa ambiental a pesar de constituir un tipo de participación B-.

Ya no vemos al murciélago como el bicho raro que hay que matar. 0 al pajarito como el bicho bonito que hay que proteger. Ahora entendemos la importancia que tienen estos animales en el ecosistema. No sólo a nivel local, a nivel global. Porque los beneficios de la selva son para todos. (24.COM_12)

En la ejecución de acciones de vigilancia, la participación se dio de forma activa. Los integrantes de los comités realizaron recorridos de monitoreo y denunciaron casos de uso de recursos naturales no permitidos. Además, algunos comités recibieron incentivos económicos o equipo de trabajo. Por eso asociamos esta fase del programa con la cooperación y la participación funcional (Tabla 1) y, en segundo término, con la participación por incentivos (Tabla 1), todas ellas de tipo $\mathrm{B}+$.

Con base en lo anterior y en el diagrama de participación, acatamiento y legitimidad (figura 1), es posible afirmar que el PVAP no produjo ningún tipo de participación que influyera en los procesos de toma de decisiones relativos a la normativa ambiental de la reserva, plasmada en el PCM. Sobre todo ésta pretendió imponerse con la implementación del PVAP, pero el desacato frecuente indica que, para los habitantes locales y dentro del marco analítico de este 
trabajo, no es legítima: “Aunque tengamos este comité, debemos poner leyes de nosotros mismos, acuerdos, que debemos respetar" (31.COM_12).

También se observó que la falta de legitimidad de la normativa ambiental oficial resulta contraproducente para los esfuerzos de la PROFEPA, porque, aunque algunos comités de vigilancia intentaron hacerla cumplir, otros dieron prioridad a los reglamentos basados en los usos y costumbres locales que a veces son contrarios a esa normativa: "Para talar, se otorga autorización verbal y se recomienda que siembren árboles. La cacería se permite cada mes o cada 15 días" (6.COM_12).

Mientras los tipos de participación que promueve el PVAP no sean de tipo C, la normativa ambiental oficial seguirá sin representar las necesidades de los habitantes de la reserva y por lo tanto seguirán ocurriendo desacatos. En este contexto, es importante subrayar también que, de acuerdo con las observaciones de esta investigación, el objetivo de protección a los recursos naturales es legítimo. Sin embargo, las restricciones de aprovechamiento de éstos no lo son. Por eso con frecuencia no son acatadas. Y es que afectan los intereses y las necesidades de los habitantes locales: "A nosotros nos interesa el bosque. Pero tenemos nuestras parcelas, con certificados parcelarios y no podemos aprovechar. ¿De qué va a vivir el ejidatario? Nosotros no nos oponemos a la reserva, pero que se haga un plan de aprovechamiento, que nos den opciones para comer" (14.COM_12).

\section{La justicia ambiental a través del PVAP}

Con base en la opinión de los integrantes de los comités de vigilancia, se observaron diversos casos en los que se omitieron los tres principios de acceso (véase tabla 2). En este sentido, la aplicación de la normativa ambiental oficial no garantizó que los miembros de los comités de vigilancia y los habitantes de la reserva satisficieran sus necesidades básicas con los recursos naturales, lo cual constituye una omisión al principio 3.1 del marco analítico:

A un árbol le cayó un rayo y lo secó. Yo lo quería aprovechar. Expliqué que formaba parte del comité, que necesitaba un permiso. Dijeron que, aunque sea madera muerta, no existe ningún permiso. Debe de existir, que venga un inspector, que observe el árbol, ya está muerto y nosotros tenemos necesidad. (9.COM_12)

Además, algunos miembros de los comités consideraron que el acceso a los recursos naturales estaba condicionado por el nivel socioeconómico de los distintos sectores poblacionales de la RBLT, lo cual constituye un ejemplo de omisiones a los principios 1.2 y 3.2 del grupo de acceso: "La gente que tiene dinero, por ejemplo, los ganaderos, talan y no pasa nada. Si un campesino tala media hectárea de selva, va a estar bajo sombra un buen tiempo. No hay mano dura para todos" (25.COM_12).

Sobre el grupo de distribución de impactos, hallamos que el PVAP infringía los principios 1.1 y 2.1 , ya que mientras los beneficios de prohibir aprovecha- 
mientos maderables son globales, los costos que de ello se derivan recaen sólo en ciertas poblaciones (véase cita 9.COM_12 en párrafos precedentes).

De forma similar, en cuanto que estrategia para la protección de los recursos naturales, el PVAP produjo algunos efectos negativos que los integrantes de los comités de vigilancia asumieron. La ejecución del programa se llevaba a cabo dentro de una estructura institucional limitada, incapaz de proveer los recursos materiales necesarios para que los comités realizaran acciones de vigilancia de manera eficaz. Además, la PROFEPA y la CONANP carecían de recursos humanos para dar seguimiento y respaldo institucional a los integrantes de los comités. "Hacemos recorridos por la laguna. Yo pongo mi lancha, pero el combustible, ¿quién lo paga? Nos toca cooperar entre nosotros. Uno pone 10 pesos; otro, 20 y así le hacemos" (5.COM_12).

Como lo muestra la cita anterior, la implementación del PVAP generaba costos económicos que recaían en los miembros de algunos comités. También se detectaron impactos sociales reflejados en conflictos entre los habitantes de las comunidades. Ambas situaciones constituyen omisiones a los principios $1.1 \mathrm{y}$ 1.2 del grupo de distribución de impactos: "Nosotros nos ponemos en mal con los mismos compañeros de aquí. Quisiéramos más apoyo, porque ellos [PROFE$\mathrm{PA}]$ se van, pero nosotros nos quedamos y con esa denuncia ya no te ven igual los compañeros" (31.COM_12).

En cuanto a los principios de inclusión, se observó que la normativa ambiental oficial no tuvo en cuenta los usos y costumbres locales ni dio espacio a su reconocimiento formal. Los miembros de los CVAP lo percibieron como una imposición que ignoraba sus arreglos locales establecidos con anterioridad. Dicha situación evidencia una omisión a los principios 2.2 y 2.3: "Desde antes de que viniera PROFEPA, teníamos nuestro reglamento interno y queremos que se nos respete. Nosotros [ya] cuidábamos, sabemos los recursos que tenemos y nuestros problemas" (27.COM_12).

Sobre la participación en la toma de decisiones, ya se ha señalado que el PVAP tampoco promovió inclusión alguna, lo cual constituye una omisión a los principios 2.2 y 2.3. Sin embargo, puede apuntarse que el PVAP, al asegurar hasta cierto punto la protección de los recursos naturales y preservarlos para beneficio de generaciones presentes y futuras, fue importante para los principios 3.3 y 3.4 correspondientes al grupo previsión. "Sí ayudaba [la PROFEPA] [...]. No hemos tenido inspector de PROFEPA desde entonces [2015] y obviamente aumentaron los ilícitos, principalmente la tala clandestina y la cacería" (36. AC_20).

La protección de los recursos naturales se consiguió también, en cierta medida, gracias a los cursos de capacitación, es decir, incentivando, mediante el conocimiento ambiental, el interés de los habitantes locales por la conservación.

\section{Efectividad del PVAP}

Con base en la información de las entrevistas, se identificaron algunas omisiones de los aspectos formales del programa. Por ejemplo, los comités de vigilancia 
se formaron sin capacitación ni evaluación previa y no siempre se alcanzó el mínimo de diez integrantes por comité. No hubo programas de trabajo específicos ni zonas definidas para las actividades y no se realizaron reuniones mensuales, como exige el Manual de vigilancia ambiental participativa (Subprocuraduría de Recursos Naturales, s. f.). La siguiente cita muestra un ejemplo de la ausencia de planes de trabajo específicos y de la inexistencia de áreas definidas para la vigilancia: "No nos corresponde ningún área. Cuando uno sale a su parcela, si ve a alguien haciendo mal uso de los recursos, se reporta conmigo" (6.COM_12).

Un aspecto formal y operativo que obstaculizaba el funcionamiento del PVAP, fue el formato para efectuar denuncias. Para que una denuncia procediera, era necesario que el acta de ésta incluyera el nombre completo, el domicilio de la persona a quien se denunciaba, la descripción del daño ambiental y los datos precisos de la parcela donde había ocurrido el daño (29.INST_12). Esto no sólo hacía difícil la ejecución formal del PVAP, sino que además incentivaba arreglos informales al margen del PCM (CONANP, 2006): "Reportamos los incidentes a la PROFEPA, pero es difícil por los datos que te piden. A veces no tenemos el nombre completo de la persona y entonces tratamos de arreglarlo a nivel local" (28.COM_12).

Otro aspecto operativo negativo fue que la falta de personal y de recursos institucionales impedía que la PROFEPA tuviera mayor presencia en las comunidades de la RBLT y diera un mejor seguimiento a los comités de vigilancia (29. INST_12). Esto se tradujo en que algunos de los miembros de los comités de vigilancia abandonaran el programa. "Dejamos el comité, porque la PROFEPA no atiende los casos cuando se amerita. Por eso muchos se han desintegrado; no hay presencia de la PROFEPA" (14.COM_12).

Sin embargo, a pesar de los problemas operativos que se detectaron y de la deserción, se pudo apreciar que los objetivos de protección ambiental, como los dedicados a impedir la tala y la cacería, se cumplieron en ciertos casos. "Al saber que fulano cuida, pues la gente se controla. Antes se escuchaban las motosierras en el manglar, ahorita ya no" (5.COM_12). "Ahorita ya se empiezan a ver de nuevo los animales y se acercan hasta las parcelas, porque ya no los molestan. Pero antes ya se los estaban acabando. Yo fui muy estricta con eso de la cacería desde que entré como presidenta del comité" (18.COM_12).

Además, como ya se ha mencionado, los cursos de capacitación produjeron un mayor conocimiento ambiental entre los integrantes de los comités, lo cual aumentó el interés por proteger los recursos naturales y respetar la normativa ambiental oficial.

No sabíamos nada de la tortuga. Como pescadores, sólo agarrábamos el huevo y lo comíamos. Ellos [las autoridades de la reserva] nos trajeron unos biólogos y nos explicaron cómo es la anidada, qué tortuga es, etcétera. La verdad es bonito cuidarlos, porque nosotros nos hemos desengañado de cómo nacen. (22.COM_12)

De esta manera, puede decirse que el PVAP alcanzaba de forma parcial el objetivo de hacer cumplir la normativa ambiental dentro de la RBLT. A veces la 
tala y la cacería pudieron impedirse. Además, el hecho de que con la interrupción del programa haya incrementado la incidencia de prácticas no sustentables prohibidas por el PCM (CONANP, 2006), valida su potencial. "Pegó fuerte el hecho de no tener al residente [delegado] de PROFEPA aquí en la zona. Yo he pedido mucho apoyo de otras instituciones para que nos echen la mano con la vigilancia. Es necesario" (34.ANT_COM_20).

\section{Discusión y conclusiones}

Antes de responder las preguntas de investigación, es preciso reconocer que el éxito de la gobernanza de la RBLT no se reduce al funcionamiento del PVAP, pero también que es un instrumento valioso y con potencial para la gestión de ésta y, en general, para este tipo de áreas naturales protegidas (ANP).

Es importante recordar que el análisis se centró en tres principios fundamentales de la gobernanza ambiental, importantes para el caso de estudio: legitimidad, justicia ambiental y efectividad, pero que no abarca la totalidad de los aspectos que componen la gobernanza.

A pesar de que los datos de campo se recabaron en 2012, el estudio es relevante porque muestra lecciones valiosas de la implementación del PVAP. Además, hay que decir que una nueva fase del programa en la RBLT podría ser de mucha utilidad en la situación actual: los aportes de este estudio resultan vigentes en ese sentido.

¿Cómo contribuía el PVAP a la instauración de un régimen de gobernanza ambiental: legítimo, justo y efectivo en la RBLT?

La figura 8 muestra los alcances del PVAP durante el periodo que se analiza. En ella identificamos dos tipos de participación: B- y B+. El proceso de conformación de los CVAP corresponde al tipo de participación $B-$, ya que consistió en la transferencia de información, referente a la existencia del PVAP, de parte de la PROFEPA hacia los habitantes de la RBLT. Como lo indican las flechas, la injerencia en la toma de decisiones respecto a la normativa ambiental en el marco de este tipo de participación fue nula. Por lo tanto, el acatamiento de dichas decisiones resultó comprometido y no se alcanzó la legitimidad. Esto quedó evidenciado con la frecuente inobservancia de las restricciones oficiales de aprovechamiento de recursos naturales y con el desacuerdo de varios integrantes de CVAP con respecto a ellas.

Por otro lado, a través de los cursos de capacitación ambiental, el PVAP acrecentó el interés de algunos de los integrantes de los CVAP en la protección de los recursos naturales. Esto constituyó una aportación importante para el principio de efectividad, porque incentivó el compromiso de algunos integrantes de los comités con la protección ambiental y facilitó el cumplimiento de la normativa ambiental, plasmada en el PMC (CONANP, 2006). Sin embargo, al ser un tipo de participación pasiva, que no tuvo injerencia en la toma de decisiones, corresponde al tipo B-. 
Figura 6. Tipos de participación, acatamiento y legitimidad en el PVAP

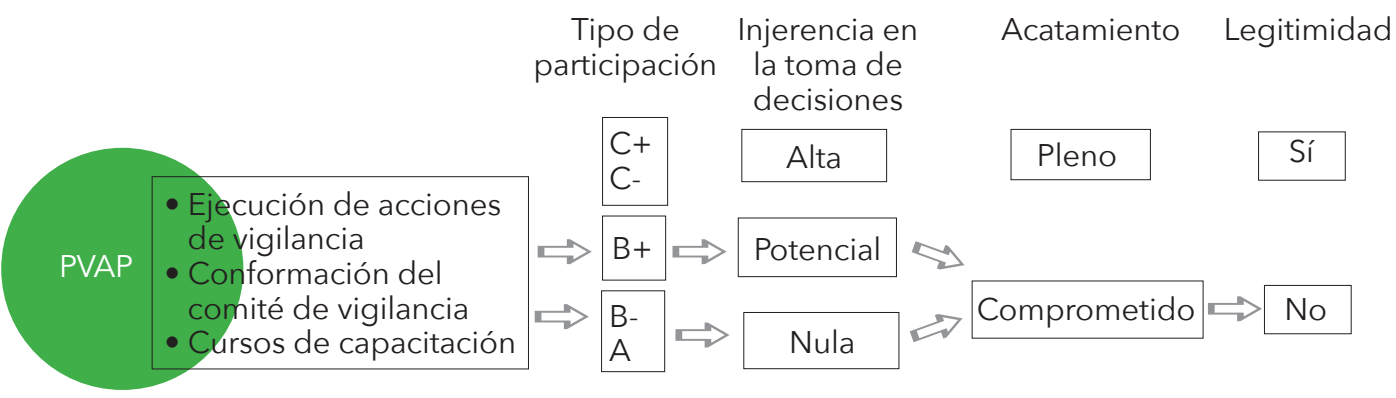

Fuente: elaboración propia, 2021.

Como se muestra en la figura 6, la participación de tipo B+ se dio en la ejecución de labores de vigilancia de los CVAP, sin que esto tuviera impactos positivos desde la perspectiva de la legitimidad. En este panorama, encontramos que el PVAP no contribuyó a la legitimidad de la gobernanza ambiental de la RBLT.

En cuanto a la justicia ambiental, se observó que a varios de los integrantes de los CVAP les parecía injusto no tener derecho al aprovechamiento de los recursos naturales de sus territorios, sobre todo cuando a lo largo del tiempo se habían ocupado de protegerlos.

Figura 7. Justicia ambiental en el PVAP

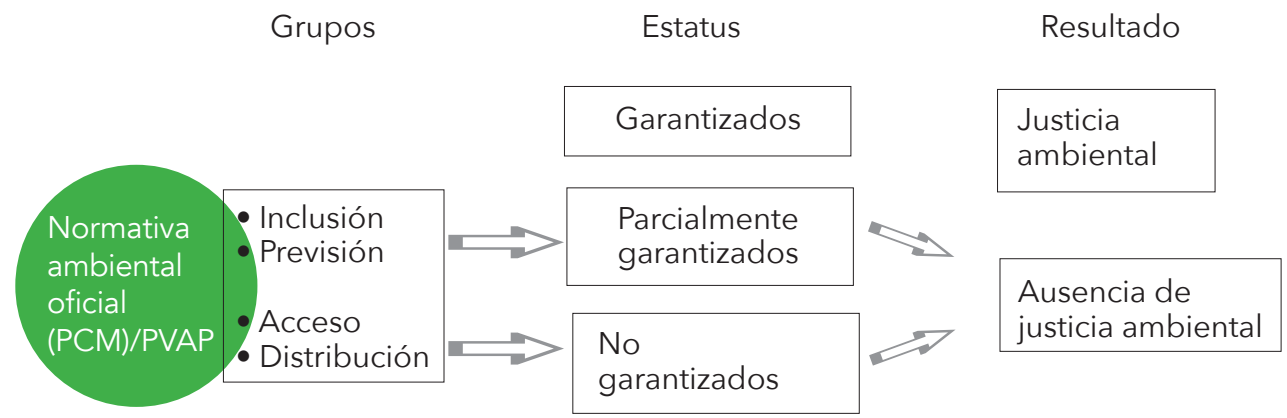

Fuente: elaboración propia, 2021.

Dichos integrantes también denunciaron que a menudo ocurrían casos en los que los habitantes de la RBLT con mayor poder económico, como los ganaderos, cometían actos ilícitos ambientales sin amonestación alguna por parte de las autoridades, mientras que, para los campesinos de menores recursos económicos, cometer el mismo tipo de actos ilícitos resultaba en sanciones fuertes. 
Además, también se vieron involucrados en conflictos con quienes hacían uso no sustentable de los recursos naturales sin que la PROFEPA los pudiera respaldar debido a las limitaciones institucionales. Por esta razón, como lo muestra la figura 7, los principios de acceso y de distribución no se garantizaron, lo cual derivó en la ausencia de justicia ambiental.

En relación con la inclusión, puede señalarse como una omisión la ausencia de participación de tipo $\mathrm{C}$ y el hecho de que los integrantes de los CVAP percibieran que los acuerdos de protección y aprovechamiento que ellos establecieron, incluso desde antes del decreto de la RBLT, no fueran respetados por las autoridades. Por eso, como lo muestra la figura 7, se considera que los principios de inclusión no se garantizaron.

Desde la perspectiva del presente trabajo, sin restar importancia a la opinión de los entrevistados, la existencia y la implementación del PVAP pueden considerarse aspectos positivos para la inclusión. El PVAP constituye una instancia concreta para la participación y tiene el potencial para mejorar. Además, su implementación, aun con los logros moderados de protección ambiental, contribuyó a veces a la preservación de los recursos naturales y, en este sentido, también dio soporte a los principios de previsión. Por tal razón, en la figura 7, tanto los principios de inclusión como los de previsión se consideran parcialmente garantizados, aunque con ello, dentro del marco analítico, no se haya logrado la justicia ambiental.

Con respecto a la efectividad, como lo muestra la figura 8, se determinó, sobre la base del marco analítico que debido al cumplimiento parcial de los objetivos, a los aspectos formales y a los aspectos operativos del PVAP, éste no resultó efectivo durante el periodo analizado.

Entre los aspectos de mayor influencia están la compleja burocracia para atender las denuncias ambientales y la baja capacidad de la PROFEPA para darle un seguimiento apropiado al PVAP y a sus comités. Esto derivó en arreglos locales, que ocurrían al margen de la normativa ambiental y de la PROFEPA, y en la deserción de algunos comités de vigilancia.

Figura 8. Efectividad del PVAP

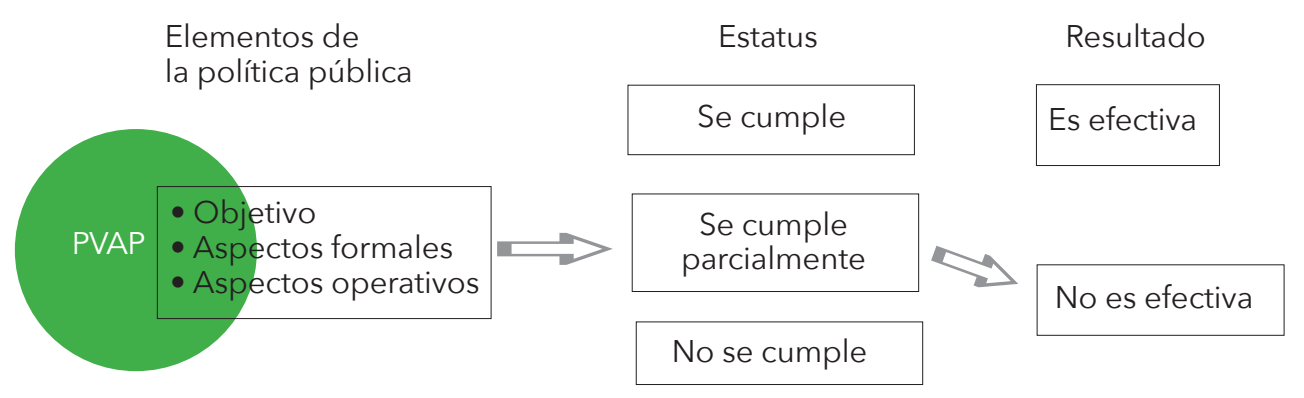

Fuente: elaboración propia, 2021. 
No obstante, pese a los problemas para cumplir los aspectos formales y operativos, se promovieron tipos de participación $B-y B+y$, sobre todo, se cumplieron, aunque de forma parcial, los objetivos de protección ambiental. A menudo los problemas de uso no sustentable de los recursos naturales lograron controlarse con la implementación del PVAP. Los testimonios de los entrevistados en este sentido y el aumento de actos ilícitos ambientales posteriores a 2015, demuestran que el programa tenía un rol valioso para la protección ambiental.

Otro aspecto rescatable es que los cursos de capacitación ambiental contribuyeron a acrecentar el interés de los integrantes de los CVAP en la protección de los recursos naturales y en el cumplimiento de la normativa ambiental oficial. Por esta razón, el hecho de que el PVAP no haya alcanzado la efectividad en el marco analítico de este trabajo, no significa que no haya sido relevante para la gobernanza ambiental de la RBLT.

¿Qué aspectos impidieron que el PVAP tuviera mayor efectividad?

Los factores que lo impidieron fueron las limitaciones materiales y humanas de la PROFEPA a escala local, la burocracia excesiva, la ausencia de justicia ambiental, referida a los principios de acceso, distribución e inclusión, y la falta de formas de participación de tipo $C$.

La PROFEPA no contaba con personal suficiente para encargarse de la protección de la RBLT. Por eso no podía dar un seguimiento adecuado a los comités de vigilancia y, cuando éstos solicitaban su intervención, la institución era incapaz de responder. Esto causó desinterés en algunos integrantes de los comités y afectó la efectividad del programa.

La burocracia para las denuncias ambientales mermó el potencial del PVAP y su efectividad. Varios de los comités de vigilancia optaron por no proceder con denuncias y tratar de solucionar los problemas a escala local sin involucrar a la PROFEPA. Este hecho tiene mucha importancia, porque si bien el tipo de participación en el marco de implementación del PVAP no abrió espacios para la toma de decisiones democráticas e inclusivas, sí creó instancias de toma de decisiones, aunque unilaterales, de parte de los CVAP que, por un lado, pudieron haber sido más convenientes para los habitantes locales y los integrantes de CVAP pero, por otro lado, tornaron más complejos los problemas de legitimidad.

La incompatibilidad entre la normativa ambiental oficial, plasmada en el PCM (CONANP, 2006) y los reglamentos basados en los usos y costumbres obstaculizó la efectividad del programa. Esto se relaciona con la falta de respeto a los principios de acceso e inclusión en el diseño y en la aplicación del PCM.

Referente al principio de distribución, se suscitaron conflictos entre los habitantes de una misma localidad debido al choque de intereses entre los comités de vigilancia que intentaban hacer cumplir el PCM y otros habitantes de la reserva que pretendían aprovechar los recursos naturales de formas no permitidas, sin que la PROFEPA pudiera intervenir debido a las limitaciones 
institucionales, lo que fue otra razón por la que a veces los comités prefirieron suspender las actividades de vigilancia. Lo mismo sucedió cuando éstas requerían recursos materiales que la PROFEPA no era capaz de proveer.

La omisión de los principios de inclusión y la ausencia de formas de participación de tipo $\mathrm{C}$ en la planeación, ejecución y evaluación de la política ambiental aplicable a la reserva, como lo contemplan el PCM y el Manual de vigilancia ambiental participativa (Subprocuraduría de Recursos Naturales, s. f.), fueron factores que impidieron que el PVAP tuviera mayor efectividad.

¿Es relevante en el contexto actual retomar el PVAP para dar soporte a la legitimidad, justicia y efectividad a la gobernanza de la RBLT?

La respuesta es afirmativa. Independientemente de otras estrategias de participación, la implementación del PVAP durante el periodo que se analiza, al articular las comunidades con la autoridad ambiental (PROFEPA), edificó una estructura social valiosa para la gobernanza del ANP que sería útil retomar en una nueva fase de implementación.

Estos comités constituyen un nodo de comunicación y cooperación entre los habitantes de la reserva y las instituciones ambientales. A pesar de los problemas en la implementación del PVAP, algunos de sus objetivos se alcanzaron, lo cual hace creer que, si se destinan mayores recursos y atención institucional, los comités de vigilancia podrían convertirse en una pieza efectiva para una buena gobernanza ambiental de la RBLT.

Para la propuesta de una nueva fase del PVAP en la RBLT, sería importante considerar que los comités de vigilancia pueden contribuir a alcanzar mayor legitimidad en la normativa ambiental aplicable a la reserva, si se vinculan a través de sus presidentes al Consejo Asesor, por ejemplo, para poder dar espacio a formas de participación de tipo $\mathrm{C}$.

La incorporación cuidadosa de los reglamentos comunitarios de aprovechamiento y protección de los recursos naturales es imperativa para mejorar la gobernanza en la RBLT, pues contribuiría a dar cumplimiento a los principios de acceso de la justicia ambiental, a la efectividad del PVAP y a la aplicación de la normativa ambiental en general.

La vinculación con otras instituciones, con los ocho ayuntamientos involucrados con la RBLT, con las ONG y con la CONANP, es significativa para robustecer los alcances del PVAP en términos de apoyo institucional y dotación de recursos materiales a los comités de vigilancia, aspecto que está contemplado en el Manual de vigilancia ambiental participativa (Subprocuraduría de Recursos Naturales, s. f.), pero que no se dio durante el periodo analizado.

Por último, los cursos de capacitación sobre temas ambientales resultaron importantes para fomentar el cumplimiento de la normativa ambiental oficial. Éste es un aspecto que debe considerarse no sólo en el contexto de los comités de vigilancia, sino también entre todos los habitantes de la reserva. 


\section{Referencias}

Abrams, P., Borrini, G., Gardner, J., y Heylings, P. (2003). Evaluating Governance: A Handbook to Accompany a Participatory Process for a Protected Area. Parks Canada and TILCEPA. Indigenous and local communities. Equity and protected areas. IUCN. Recuperado de https: / / portals.iucn.org/library/ node/ 12430

Adams, W. M. , y Hutton, J. (2007). People, parks and poverty: political ecology and biodiversity conservation. Conservation and Society (5), 147-83. Recuperado de http: / / www.conservationandsociety.org/text.asp?2007/5/2/147/49228

Adger, W. N., Brown, K., Fairbrass, J., Jordan, A., Paavola, J., Rosendo, S., y Seyfang, G. (2003). Governance for sustainability: towards a "thick" analysis of environmental decisionmaking. Environment and Planning A, 35(6), 10951110. doi: https://doi.org/10.1068/a35289

Alfie, M. (2011). Introducción. En M. Alfie (ed.), Comprometidos para negociar conflicto y gobernanza ambiental (Holanda, Canadá y México) (pp. 15-24). Ciudad de México: Universidad Autónoma Metropolitana (UAM), Unidad Cuajimalpa y Juan Pablos Editor.

Alfie, M., Díaz, L., y Castañeda, R. (2011). Una ventana de oportunidad: la gobernanza ambiental, nuevo instrumento de política. En M. Alfie (ed.), Comprometidos para negociar conflicto y gobernanza ambiental (Holanda, Canadá y México) (pp. 25-75). México: UAM-Cuajimalpa y Juan Pablos Editor.

Arnstein, S. R. (1969). A ladder of citizen participation. Journal of the American Institute of Planners, 35(4), 216-224. doi: https://doi. org/10.1080/01944366908977225

Aydin, B. (2020). Global climate governance between state and non-state actors: dynamics of constatation and re-legitimization. Marmara Üniversitesi SiyasalBilimler Dergesi, 8(Özel Sazi), 59-79.

BancoMundial (BM). (1992). Governanceand development. Washington. Recuperado de http://documents.worldbank.org/curated/en/604951468739447676/ Governance-and-development

Batisse, M. (1993). Biosphere reserves: an overview. Nature and Resources, 29(1-4).

Brenner, L. (2009). Aceptación de políticas de conservación ambiental: el caso de la Reserva de la Biosfera Mariposa Monarca. Economía, Sociedad y Territorio, 9(30), 259-295. doi: https://doi.org/10.22136/est002009175

Brenner, L. (2012). Desafíos para la gobernanza ambiental en México: el caso de las Reservas de la Biosfera. En R. Rosales, L. Brenner y C. Mendoza (eds.), Geografía económica y social: actores, instituciones y procesos globales (pp. 207-230). Ciudad de México: Siglo XXI Editores y UAM.

Brenner, L. (2015). Introducción: procesos de construcción de la gobernanza. En L. Brenner y R. Rosales (eds.), Geografía de la gobernanza: dinámicas multiescalares de los procesos económico-ambientales (pp. 7-19). Ciudad de México: Siglo XXI Editores y UAM. 
Brock, M. J. (2020). Unfair inequality, governance and individual beliefs. Journal of Comparative Economics, 48(3), 658-687. doi: https://doi.org/10.1016/j. jce.2020.03.001

Cano, F. (2008) La participación ciudadana en las políticas públicas de lucha contra la corrupción: respondiendo a la lógica de la gobernanza. Estudios Políticos (33), 147-177. Recuperado de https: / / revistas.udea.edu.co/index. php/estudiospoliticos/article/view/1946

Comisión Nacional de Áreas Naturales Protegidas (CONANP). (2006). Programa de Conservación y Manejo Reserva de Biosfera Los Tuxtlas. Ciudad de México: Comisión Nacional de Áreas Naturales Protegidas. Recuperado de https:// www.conanp.gob.mx/que_hacemos/pdf/programas_manejo/tuxtla_final. pdf

Comisión Nacional de Áreas Naturales Protegidas (CONANP). (2017). Consejo Asesesor de la Reserva de Biosfera Los Tuxtlas. Comisión Nacional de Áreas Naturales Protegidas. Gobierno de México. Recuperado de https: / /www.gob. $\mathrm{mx} /$ conanp/acciones-y-programas/consejo-asesor-de-la-reserva-de-la-biosfera-los-tuxtlas

Comisión Nacional de Áreas Naturales Protegidas (CONANP). (2018). Programas de manejo de las áreas naturales protegidas de México. Acciones y programas. Comisión Nacional de Áreas Naturales Protegidas. Gobierno de México. Recuperado de https://www.gob.mx/conanp/acciones-y-programas/programas-de-manejo

Comisión Nacional de Áreas Naturales Protegidas (CONANP). (2020). Programa Nacional de Áreas Naturales Protegidas 2020-2024. Gobierno de México. Recuperado de https://www.gob.mx/conanp/documentos/programa-nacional-de-areas-naturales-protegidas-2020-2024?idiom=es

Cueto-García, J. (2016). Gobernanza ambiental en la Reserva de Biosfera Los Tuxtlas, Veracruz. El papel de los comités de vigilancia ambiental participativa. UAM-Iztapalapa (tesis de licenciatura). Recuperado de http://dcsh. izt.uam.mx/licenciaturas/geografiahumana/wp-content/uploads/2019/07/ Tesina-Jorge-Cueto-2016.pdf

Diario Oficial de la Federación (DOF). (2009). Aviso por el que se informa al público en general que la Comisión Nacional de Áreas Naturales Protegidas ha concluido la elaboración del Programa de Manejo de la Reserva de la Biosfera Los Tuxtlas, ubicada en los municipios de Ángel R. Cabada, Catemaco, Mecayapan, Pajapan, San Andrés Tuxtla, Santiago Tuxtla, Soteapan y Tatahuicapan de Juárez, en el Estado de Veracruz. Recuperado de https: // simec.conanp.gob.mx/pdf_pcym/138_DOF.pdf

Díaz, A. (2010). Ecoturismo comunitario y género en la Reserva de la Biosfera de Los Tuxtlas (México). PASOS. Revista de Turismo y Patrimonio Cultural, 8(1), 151-165. doi: https://doi.org/10.25145/j.pasos.2010.08.012

Durand, L., y Ruiz, J. (2009). Estaciones biológicas y participación social: la experiencia de la Universidad Nacional Autónoma de México en Los Tuxtlas, Veracruz, México. Ambiente \& Sociedade, 12(2), 325-340. doi: https://doi. org/10.1590/S1414-753X2009000200008 
Ferrando, J. (1971). Poder y legitimidad. Revista de Estudios Políticos (180), 5-28. Recuperado de https://dialnet.unirioja.es/servlet/articulo?codigo $=1948024$

Fontaine, G., y Velasco, S. (2011). La conceptualización de la gobernanza. De lo descriptivo a lo analítico. En K. Andrade (coord.), Gobernanza ambiental en Bolivia y Perú. Gobernanza en tres dimensiones: de los recursos naturales, la conservación en áreas protegidas y los pueblos indígenas (pp. 25-40). Quito: Facultad Latinoamericana de Ciencias Sociales (FLACSO-Ecuador).

García, J. P. (2010). Prácticas y políticas exitosas para promover la mejora regulatoria y el emprendimiento a nivel subnacional. Documentos de trabajo de la OCDE sobre gobernanza pública (No. 18). Recuperado de https:/ /www. oecd.org/gov/regulatory-policy/46003827.pdf

Guevara, S., Laborde, J., y Sánchez, G. (1999). La Reserva de la Biosfera Los Tuxtlas. Programa de Cooperación Sur-Sur sobre Desarrollo Socioeconómico y Ambiente Adecuado en los Trópicos Húmedos. Documentos de Trabajo 29(8). Recuperado de https://unesdoc.unesco.org/ark:/48223/pf0000121445

Halffter, G. (1981). The Mapimi Biosphere Reserve: local participation in conservation and development. Ambio, 10(2/3), 93-96. Recuperado de http:// www.jstor.org/stable/4312648

Halffter, G. (1988). El concepto de reserva de la biosfera. En C. Montaña (ed.), Estudio integrado de los recursos vegetación, suelo y agua en la Reserva de la Biosfera de Mapimí, Vol. I. (pp. 19-44). México: Instituto de Ecología. Recuperado de https://horizon.documentation.ird.fr/exl-doc/pleins_textes/ divers14-07/26543.pdf

Halffter, G. (2011). Reservas de la biosfera: problemas y oportunidades en México. Acta Zoológica Mexicana, 27(1), 177-189.

Hervé, D. (2010). Noción y elementos de la justicia ambiental: directrices para su aplicación en la planificación teritorial y en la evaluación ambiental estratégica. Revista de Derecho, 23(1), 9-36. doi: https://doi.org/10.4067/ s0718-09502010000100001

Hidalgo, R. (2009). De selva a potrero: desencuentros entre las formas culturales de apropiación territorial y las políticas agrarias y ambientales. El caso de la micro-región Perla del Golfo, Sur de Veracruz (tesis de licenciatura). Escuela Nacional de Antropología e Historia (ENAH).

Jacob, K., King, P., Mangalagiu, D., y Rodríguez-Labajos. (2019). Approach to assessment of policy effectiveness. (2019). En UN Environment (ed.), Global Environment Outlook-GEO-6: Healthy Planet, Healthy People (pp. 272-281). Cambridge: Cambridge University Press. doi: https://doi. org/10.1017/9781108627146.016

Lancaster, C. (1993). Governance and Development: the views from Washington. IDS Bulletin, 24(1), 9-15. doi: https://doi.org/10.1111/j.1759-5436.1993. mp24001003.x

Legorreta, D. (2009). Democracia, desigualdad y política ambiental: un enfoque interdisciplinario para una política democrática ambiental. Las Jornadas Anuales de Investigación del CEIICH-UNAM-2008. Universidad Nacional Autónoma de México (UNAM). 
Martínez-Alier, J. (1996). Introducción. Justicia ambiental, globalismo y sustentabilidad. El sur del planeta. Ecología Política. Cuadernos de Debate Internacional (10), 5-6. Recuperado de https://www.ecologiapolitica.info/?product $=10$-ecologia-politica

Milano, F. (2017). From the classic representative decision making process to participatory decision-making process: A new Caribbean context En V. Espinoza, C. M. Taveras y D. Andrade (eds.), Three are Better than One. Government, Civil Society, Private Sector:Joint Efforts in Caribbean Countries toward Sustainable Development (pp. 6-10). Recuperado de https:// publications.iadb.org/publications/english/document/IDB_The_Caribbean_ Web_004_1.pdf

Organización de las Naciones Unidas para la Educación, la Ciencia y la Cultura (UNESCO). (2016). Plan de Acción de Lima para el Programa sobre el Hombre y la Biosfera (MAB) de la UNESCO y su Red Mundial de Reservas de Biosfera (2016-2025) UNESCO, Congress World Network of Biosphere Reserves. Lima, Perú. Recuperado de http://www.unesco.org/new/fileadmin/MULTIMEDIA/ $\mathrm{HQ} / \mathrm{SC} / \mathrm{pdf} /$ Lima_Action_Plan_es_final.pdf

Paré, L., y Fuentes, T. (2007). Gobernanza ambiental y políticas públicas en áreas naturales protegidas. Lecciones desde Los Tuxtlas. Ciudad de México: UNAM-Instituto de Investigaciones Sociales (IIS).

Pretty, J. (1995). The many interpretations of participation. Focus (16), 4-5.

Ramírez, F. (2011). Actualización de la tasa de cambio del uso del suelo en la Reserva de la Biosfera Los Tuxtlas. Informe final. CONANP. Recuperado de https://simec.conanp.gob.mx/pdf_evaluacion/tuxtlas.pdf

Reyes, V. (2016). Urge inspector de PROFEPA en Catemaco. Informantes en Red. Recuperado de https://www.informantesenred.com/urge-inspector-de-profepa-en-catemaco/

Riechmann, J. (2003). Tres principios básicos de justicia ambiental. Revista Internacional de Filosofía Política (21), 103-120. Recuperado de https:// dialnet.unirioja.es/servlet/articulo?codigo=714769

Robles, B. (2011). La entrevista en profundidad: una técnica útil dentro del campo antropofísico. Cuicuilco, 18(52), 39-49. Recuperado de http://www.scielo.org.mx/scielo.php?script=sci_arttext\&pid=S0185-16592011000300004\&lng=es\&tlng=es

Rodríguez-Franco, I., Rodríguez, G., Muñoz, P., García, D. , y Vázquez, M. (2020). Participación social en la gobernanza del Área de Protección de Flora y Fauna Islas Golfo de California. región y sociedad, 32, e 1323. doi: https://doi. org/10.22198/rys2020/32/1323

Secretaría de Medio Ambiente y Recursos Naturales (SEMARNAT). (2012). Ley General de Equilibrio Ecológico y Protección al Ambiente (LEGEEPA). Recuperado de https://www.senado.gob.mx/comisiones/desarrollo_social/ docs/marco/Ley_GEEPA.pdf

Secretaría de Medio Ambiente y Recursos Naturales (SEMARNAT). (2020). Comités de Vigilancia Ambiental Participativa. Consulta Temática. Gobierno de México. Recuperado de http://dgeiawf.semarnat.gob.mx:8080/ibi_apps/ WFServlet?|BIF_ex=D4_R_PROFEPA01_05\&IBIC_user=dgeia_mce\&IBIC_pass=dgeia_mce 
Siemens, A. (2009). Una manera de ver Los Tuxtlas. Paisajes de Mesoamérica. Comisión Nacional para el Conocimiento y Uso de la Biosiversidad (CONABIO). Recuperado de https://www.biodiversidad.gob.mx/corredor/cobiored/index.php/publicaciones/item/146-una-manera-de-ver-los-tuxtlas-paisaje-de-mesoamerica

Stocker, G. (1998). Governance as theory: five propositions. International Social Sciences Journal (68), 15-24. doi: https: / / doi.org/10.1111/issj.12189

Stoll-Kleemann, S., y O'Riordan, T. (2002). From participation to partnership in biodiversity protection: Experience from Germany and South Africa. Society and Natural Resources, 15(2), 161-177. doi: https://doi. org/10.1080/089419202753403337

Subprocuraduría de Recursos Naturales. (s. f.). Manual de vigilancia ambiental participativa. Ciudad de México: Procuraduría Federal de Protección al Ambiente (PROFEPA) y SEMARNAT.

Toledo, V., Alarcón-Chaires, P., Moguel, P., Olivo, M., Cabrera, A., Leyequien, E., y Rodríguez-Aldabe, A. (2002). Biodiversidad y pueblos indios en México y Centroamérica. Biodiversitas (43), 2-8.

Vasilachis de Gialdino, I. (2006). La investigación cualitativa. En Vasilachis de Gialdino (coord.), Estrategias de investigación cualitativa (pp. 23-64). Barcelona: Biblioteca de Educación y Gedisa Editorial.

Vega-Leinert, A. C. de la, y Stoll-Kleemann, S. (2012). Retos y oportunidades en el manejo de la biodiversidad: el caso de las reservas de la biosfera. En R. Rosales, L. Brenner y C. Mendoza (coords.), Geografía económica y social. Actores, instituciones y procesos globales (pp. 187-206). Ciudad de México. Siglo XXI Editores y UAM.

Velázquez, E., y Ramírez, F. (2015). Disputas y adaptaciones en torno al uso de los Recursos en la Reserva de la Biosfera "Los Tuxtlas", Veracruz (México). Revista de Estudos e Pesquisas sobre as Américas, 9(3), 1-28. Recuperado de https: / / periodicos.unb.br/index.php/repam/article/view/16033 